\title{
Serum inhibitory and bactericidal titers in the clinical management of bacterial infections
}

\author{
Ioana Berciu ${ }^{1,2^{*}}$, Oana Săndulescu ${ }^{1,2}$, Anca Streinu-Cercel ${ }^{1,2}$, Adrian Streinu-Cercel ${ }^{1,2}$ \\ From The 10th Edition of the Scientific Days of the National Institute for Infectious Diseases "Prof Dr Matei \\ Bals" \\ Bucharest, Romania. 15-17 October 2014
}

\section{Background}

The clinical management of bacterial infection computes factors related to bacteria (e.g., resistance profile [1]), antibiotics (e.g., activity spectrum, distribution volume, etc.), host characteristics (e.g., vascularization of the infected tissue, effectiveness of host defenses, etc.), as well as pharmacokinetic (PK) parameters [2]. The serum inhibitory (SIT) and bactericidal titers (SBT) are laboratory tests that simulate the interactions between antibiotics and bacteria in the human body milieu.

\section{Methods}

In the Emergency Laboratory of the Adults 2 Clinical Ward of the National Institute for Infectious Diseases "Prof. Dr. Matei Balş", we consistently perform SIT and SBT in complicated cases of bacterial infections. We have retrospectively collected and analyzed data from such tests performed between 2012 and 2014 and correlated the results with the patient's overall clinical evolution. We present the descriptive results.

\section{Results}

We have analyzed 89 cases. The serum antibiotics tested were: linezolid (15 cases, 16.9\%), carbapenems (12 cases, $13.5 \%)$ with (5 cases) and without (7 cases) colistin, aminopenicillins (10 cases, $11.2 \%$ ), and in smaller percentages: oxacillin, tigecycline, fluoroquinolones, trimethoprim/sulfamethoxazole, glycopeptides, aminoglycosides, ceftaroline and other cephalosporins.

In most cases serum samples were collected at the time of peak PK, with the exception of three cases where the trough concentration was examined instead. The tested germs were mostly Staphylococcus spp.

\footnotetext{
* Correspondence: ioana_ib@yahoo.com

${ }^{1}$ Carol Davila University of Medicine and Pharmacy, Bucharest, Romania
}

Full list of author information is available at the end of the article
(51.7\%), followed by Enterococcus spp. (14.6\%), Streptococcus spp. (9\%) and Gram-negative bacilli (24.7\%) such as: E. coli, Klebsiella spp. and Pseudomonas spp. The strains had been isolated from blood cultures (49.4\%), cutaneous wounds $(23.6 \%)$, tracheal aspirate $(13.5 \%)$ and urine samples $(7.9 \%)$.

SIT ranged from $1 / 2(12.4 \%)$ to $1 / 512(5.6 \%)$, but only in 20 cases $(22.4 \%)$ the titers were in the therapeutic comfort range of $1 / 64$ to $1 / 512$. SBT ranged from $0(11.2 \%)$ to $1 / 256$ (6.7\%). SIT and SBT were equal and in the comfort range for 2 strains of wound Staphylococcus, 4 strains of blood culture Staphylococcus, and 3 strains of tracheal aspirate E. coli.

\section{Conclusion}

Interdisciplinary patient management and good collaboration with the bacteriology laboratory all contribute to establishing, maintaining and adapting targeted antimicrobial therapy.

\section{Acknowledgements \\ 1) POSDRU/159/1.5/S/137390. \\ 2) Carol Davila University of Medicine and Pharmacy, Young Researchers Projects Grant Competition, contract number 28.336/04.11.2013.}

\section{Authors' details}

${ }^{1}$ Carol Davila University of Medicine and Pharmacy, Bucharest, Romania. ${ }^{2}$ National Institute for Infectious Diseases "Prof. Dr. Matei Balş", Bucharest, Romania.

\section{Published: 15 October 2014}

\section{References}

1. Streinu-Cercel O: Expected sensitivity to antibiotics in bacterial infections. GERMS 2013, 3:7.

2. Kiang TK, Häfeli UO, Ensom MH: A comprehensive review on the pharmacokinetics of antibiotics in interstitial fluid spaces in humans: implications on dosing and clinical pharmacokinetic monitoring. Clin Pharmacokinet 2014, 53:695-730. 
doi:10.1186/1471-2334-14-57-020

Cite this article as: Berciu et al:: Serum inhibitory and bactericidal titers

in the clinical management of bacterial infections. BMC Infectious

Diseases 2014 14(Suppl 7):O20.

Submit your next manuscript to BioMed Central and take full advantage of:

- Convenient online submission

- Thorough peer review

- No space constraints or color figure charges

- Immediate publication on acceptance

- Inclusion in PubMed, CAS, Scopus and Google Scholar

- Research which is freely available for redistribution

Submit your manuscript at 